\title{
Probable linezolid-induced pancytopenia
}

\author{
Nita Lakhani BScPhm ${ }^{1}$, William Thompson MD FRCPC ${ }^{2}$, Anne Marie Bombassaro BScPhm PharmD ${ }^{1}$
}

\begin{abstract}
A 75-year-old male outpatient with cardiac disease, diabetes, chronic renal insufficiency and iron deficiency anemia was prescribed linezolid $600 \mathrm{mg}$ twice daily for a methicillin-resistant Staphylococcus aureus diabetic foot osteomyelitis. After one week, his blood counts were consistent with baseline values. The patient failed to return for subsequent blood work. On day 26 , he was admitted to hospital with acute renal failure secondary to dehydration, and was found to be pancytopenic (erythrocytes $2.5 \times 10^{12} / \mathrm{L}$, leukocytes $2.9 \times 10^{9} / \mathrm{L}$, platelets $59 \times 10^{9} / \mathrm{L}$, hemoglobin $\left.71 \mathrm{~g} / \mathrm{L}\right)$. The patient was transfused, and linezolid was discontinued. His blood counts improved over the week and remained at baseline two months later.

The patient's decline in blood counts from baseline levels met previously established criteria for clinical significance. Application of the Naranjo scale indicated a probable relationship between pancytopenia and linezolid.

Clinicians should be aware of this rare effect with linezolid, and prospectively identify patients at risk and emphasize weekly hematological monitoring.
\end{abstract}

\section{Pancytopénie probablement induite par le linézolide}

On a prescrit $600 \mathrm{mg}$ de linézolide deux fois par jour à un homme de 75 ans non hospitalisé, mais atteint d'une maladie cardiaque, de diabète, d'insuffisance rénale chronique et d'anémie ferriprive, pour une ostéomyélite à staphylocoque doré compliquant un pied diabétique. Après une semaine, sa formule sanguine était comme au départ. Le patient n'est pas revenu pour les autres prises de sang de suivi. Au jour 26, il a été admi à l'hôpital pour insuffisance rénale aiguë secondaire à la déshydratation. Le patient présentait une pancytopénie (érythrocytes $2,5 \times 10^{12} / \mathrm{L}$, leucocytes $2,9 \times 10^{9} / \mathrm{L}$, plaquettes $59 \times 10^{9} / \mathrm{L}$, hémoglobine $\left.71 \mathrm{~g} / \mathrm{L}\right)$. Le patient a été transfusé, et le linézolide a été suppriemé. La formule sanguine du patient s'est améliorée au cours de la semaine suivante, et les valeurs de départ se maintenaient toujours deux mois plus tard.

La baisse de la formule sanguine du patient par rapport aux données de départ répondait aux critères de portée clinique significative établis. L'application de l'échelle de Naranjo indiquait un lien probable entre la pancytopénie et le linézolide.

Les médecins doivent être au courant de cet effet peu commun associé au linézolide, tenter d'identifier prospectivement les patients à risque et insister sur l'importance des tests hématologiques hebdomadaires.

Key Words: Adverse reaction; Linezolid; Pancytopenia

L inezolid, the first marketed oxazolidinone antimicrobial, has

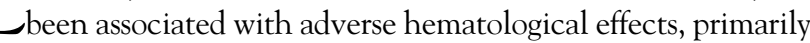
thrombocytopenia $(1,2)$. A case of pancytopenia believed to be associated with linezolid therapy is presented. The severity of this adverse event emphasizes the importance of both the prescription of linezolid for well-defined indications and appropriate hematological monitoring during therapy.

\section{CASE PRESENTATION}

A 75-year-old male outpatient was prescribed oral linezolid $600 \mathrm{mg}$ twice daily for one month in January 2003 (day 1) to treat a methicillin-resistant Staphylococcus aureus diabetic foot osteomyelitis. Linezolid was selected as the initial therapy because the patient refused intravenous vancomycin and the microorganism was resistant to other oral antibiotics.

The patient had underlying cardiac and peripheral vascular disease, diabetes mellitus, chronic renal insufficiency (baseline serum creatinine approximately $200 \mu \mathrm{mol} / \mathrm{L}$ ) and anemia. He had been receiving a medication regimen consisting of insulin, furosemide, metolazone, levothyroxine, ferrous gluconate, nitroglycerin, metoprolol and enteric-coated acetylsalicylic acid for nine months. The patient had no known drug allergies.

At follow-up on day 7, the patient's blood counts remained within an acceptable range relative to his baseline values. The patient failed to return for further evaluation and scheduled blood work. On day 26 of therapy, the patient was admitted to London Health Sciences Centre (London, Ontario) with acute on chronic renal failure (serum creatinine $358 \mu \mathrm{mol} / \mathrm{L}$ ) due to dehydration. The dehydration was secondary to a threeday history of vomiting and decreased appetite with concurrent overdiuresis. The patient denied fever, chills, night sweats, headaches, arthralgias, rash, chest pain, cough, diarrhea, abdominal pain and bleeding. On physical examination, petechiae were noted on the limbs. The patient's hematology results were consistent with pancytopenia, and linezolid was the suspected cause. With the initiation of intravenous hydration and blood transfusion and the discontinuation of linezolid, the patient's renal function and blood counts improved by the following week. On day 35, the patient initiated a four-week course of intravenous vancomycin for the foot infection.

${ }^{1}$ London Health Sciences Centre; ${ }^{2}$ Division of Infectious Diseases, University of Western Ontario, London, Ontario

Correspondence: Anne Marie Bombassaro, London Health Sciences Centre - Victoria Campus, Pharmacy Department,

Office B-6, 800 Commissioner's Road East, London, Ontario N6A 4G5. Telephone 519-685-8500 ext 52040, fax 519-685-8304,

e-mail annemarie.bombassaro@lhsc.on.ca

Received for publication June 3, 2004. Accepted September 17, 2004 
TABLE 1

Hematological parameters corresponding to day from the start of linezolid therapy

\begin{tabular}{lcccc}
\hline Parameter & Baseline & Day 26* & Day 33 & Day 76 \\
\hline Erythrocytes $\left(\times 10^{12} / \mathrm{L}\right)$ & 3.7 & 2.5 & 3.3 & 4.0 \\
Hemoglobin $(\mathrm{g} / \mathrm{L})$ & 104 & 71 & 94 & 104 \\
Leukocytes $\left(\times 10^{9} / \mathrm{L}\right)$ & 6.9 & 2.9 & 8.4 & 6.7 \\
Platelets $\left(\times 10^{9} / \mathrm{L}\right)$ & 201 & 59 & 172 & 203 \\
\hline
\end{tabular}

${ }^{\star}$ End of therapy

The patient was readmitted in May 2003 (day 76) for an unrelated illness, at which time his blood counts remained consistent with baseline values observed in January 2003. His medication regimen was the same as that taken at baseline, with the exception of the linezolid.

Table 1 summarizes the patient's hematological parameters at baseline (day 1), end of therapy (day 26), one week postlinezolid discontinuation (day 33) and follow-up (day 76). Figure 1 illustrates the changes as a percentage of baseline values over time.

\section{DISCUSSION}

Linezolid is a synthetic antibiotic that belongs to a new class of antimicrobials called the oxazolidinones (1). Linezolid's potent activity against Gram-positive bacteria, including methicillinresistant $S$ aureus, penicillin-resistant streptococci and vancomycin-resistant enterococci, and its excellent bioavailability after oral dosing have made it an important addition to the antibiotic armamentarium (3).

Time- and dose-dependent reversible myelosuppression was observed in preclinical studies with linezolid (4). As stated by the manufacturer (1), substantially abnormal hematology values were defined in clinical trials as less than $75 \%$ (less than $50 \%$ for neutrophils) of the lower limit of normal and/or baseline. The decrease in hematological values observed from baseline to day 26 in our patient met this definition (1), as well as clinical significance criteria specified by others (2).

A summary (4) of the hematological effects observed during clinical trials reported thrombocytopenia in $2.4 \%$ of linezolid patients versus $1.5 \%$ for controls, while pancytopenia was not observed. However, in the compassionate use program (5), pancytopenia occurred in two of 828 treatment courses. A MEDLINE search performed without restrictions until June 1, 2004, using the terms 'linezolid' and 'pancytopenia(s)' yielded three reports involving four cases of pancytopenia associated with linezolid therapy (6-8).

In the first six months of approved linezolid use in the United States, 72 cases of hematological abnormalities were recorded among 55,000 patients, and pancytopenia accounted for 13 of these cases (2). A search requested from the Canadian Adverse Drug Reaction Monitoring Program (CADRMP) database (from the date of linezolid marketing to April 30, 2003) revealed no reports of pancytopenia, while a World Health Organization database search involving pancytopenia and linezolid yielded 37 reports. Because the CADRMP coordinates voluntary reporting of adverse reactions in Canada, mainly by health professionals, estimates of incidence or causality cannot be established (CADRMP, personal communication).

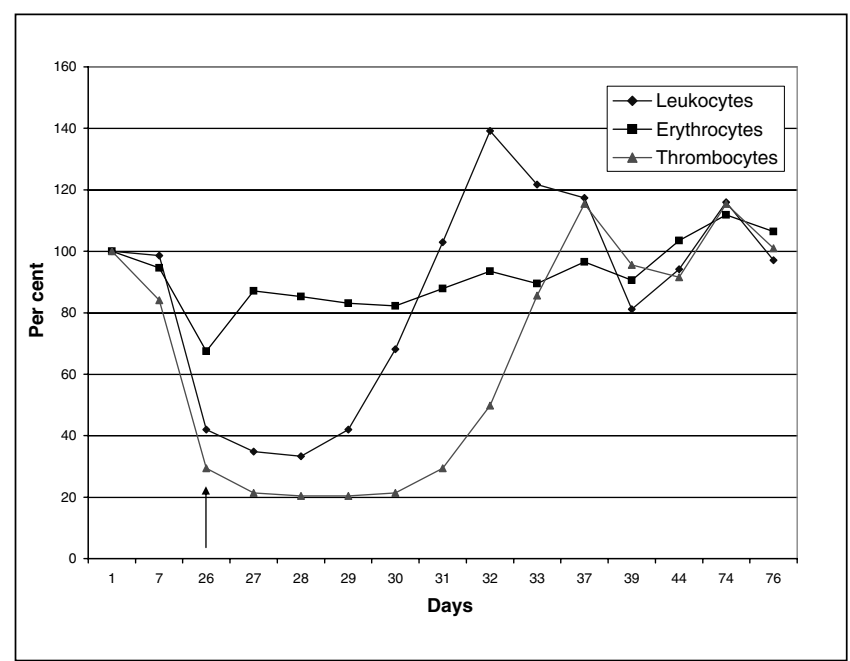

Figure 1) The change in leukocytes, erythrocytes and platelets as a percentage of baseline values (day 1) over time (in days). The arrow indicates when the patient was transfused and linezolid was discontinued

The Naranjo probability scale (9) was used to determine the likelihood of association between pancytopenia and linezolid therapy in the present case. Our patient met criteria for a score of 7 , suggesting a probable association. Possible confounding factors included the presence of a foot infection, preexisting anemia and chronic renal disease. It is unlikely that these conditions would cause an acute pancytopenia with a rapid recovery, after intravenous fluids and blood transfusion, in the absence of alternate antibiotic therapy. A viral infection was a remote possibility but was not considered given the absence of fever, rash and arthritis. The patient's other drugs were considered unlikely culprits because he had been taking them during, and for several months before and after, the adverse event.

The linezolid product monograph issues a warning to clinicians concerning myelosuppression (1). The manufacturer recommends that complete blood counts are monitored weekly, particularly for those patients who receive linezolid for longer than 14 days, those with pre-existing myelosuppression, those with a chronic infection who have received previous or concomitant antibiotic therapy, and those receiving concomitant drugs that produce bone marrow suppression (1). Our patient possessed the first two of these specified risk factors and, unfortunately, failed to return to clinic for scheduled blood work.

In previously published reports $(6,7)$, pancytopenia has been noted after 20 and 28 days of therapy. This time frame is similar to that of the present case and to that of cases reported by Kuter and Tillotson (2), in which 11 of 13 cases of pancytopenia occurred after at least three weeks of therapy. Hematological parameters improved seven to 14 days after the discontinuation of linezolid in the present patient, as was observed in previously published descriptions $(6,7)$.

The present case and cases previously published (6-8) involved elderly patients (60 years of age or older) receiving linezolid $600 \mathrm{mg}$ twice daily. In addition, our patient had chronic renal insufficiency as a comorbid condition. Age has not been found to significantly affect linezolid's pharmacokinetics after single $600 \mathrm{mg}$ oral doses (10). Although approximately $30 \%$ of a dose is excreted unchanged via the kidney, the overall clearance of linezolid is not markedly altered in 
renal insufficiency (11). Therefore, the manufacturer does not consider dose adjustment necessary for geriatric patients or for patients with renal impairment (1).

Linezolid is metabolized by oxidation yielding two metabolites that do not have significant antibacterial activity (12). Multiple dose administration to patients with severe renal insufficiency results in plasma metabolite concentrations approximately 10 -fold higher than in subjects with normal renal function (12). The overall clinical significance of metabolite accumulation has not been established, leading the manufacturer (1) and others (12) to suggest that linezolid should be used with caution in patients with severe renal insufficiency.

The mechanism of linezolid-induced hematological adverse events is unclear at the present time. Controversy exists as to whether linezolid myelotoxicity resembles that of chloramphenicol $(13,14)$. Reversible chloramphenicol bone marrow suppression is dose-dependent and is thought to occur by the inhibition of mitochondrial protein synthesis (15). The reversibility of linezolid's hematological effects $(2,4,6-8,13)$

\section{REFERENCES}

1. Zyvoxam product monograph. Compendium of Pharmaceutical Specialties. Ottawa: Canadian Pharmacists Association, 2004:2341-4.

2. Kuter DJ, Tillotson GS. Hematologic effects of antimicrobials: Focus on the oxazolidinone linezolid. Pharmacotherapy 2001;21:1010-3.

3. Moellering RC. Linezolid: The first oxazolidinone antimicrobial. Ann Intern Med 2003;138:135-42.

4. Gerson SL, Kaplan SL, Bruss JB, et al. Hematologic effects of linezolid: Summary of clinical experience. Antimicrob Agents Chemother 2002;46:2723-6.

5. Birmingham MC, Rayner CR, Meagher AK, Flavin SM, Batts DH, Schentag JJ. Linezolid for the treatment of multidrug-resistant, Gram-positive infections: Experience from a compassionate-use program. Clin Infect Dis 2003;36:159-68.

6. Nimeiri HS, Nemiary DS. Challenges with linezolid therapy and reversible pancytopenia. Ann Hematol 2003;82:533.

7. Halpern M. Linezolid-induced pancytopenia. Clin Infect Dis 2002;35:347-8.

8. Tahir N. Serotonin syndrome as a consequence of drug-resistant infections: An interaction between linezolid and citalopram. J Am Med Dir Assoc 2004;5:111-3. suggests that a similar mechanism may be involved $(6,13,14)$. Laboratory evidence (14) has suggested that linezolid-induced thrombocytopenia may be an immune-mediated phenomenon of platelet destruction.

\section{CONCLUSIONS}

It is important for clinicians to be aware of the potential hematological effects, including pancytopenia, associated with linezolid and to prospectively identify patients at risk. Further clinical experience with the drug will elucidate if advanced age, renal insufficiency and metabolite accumulation contribute to its toxicity. Limiting the use of linezolid to patients with welldefined indications such as resistant Gram-positive infections or intolerance to standard agents, recognizing risk factors, and adhering to monitoring recommendations will minimize the number of patients likely to experience serious hematological events. Consideration should also be given to limiting the amount of medication dispensed at any one time to a duration of one to two weeks to encourage patients to return for appropriate follow-up, including hematological monitoring.

9. Naranjo CA, Busto U, Sellers EM, et al. A method for estimating the probability of adverse drug reactions. Clin Pharmacol Ther 1981;30:239-45.

10. Sisson TL, Jungbluth GL, Hopkins NK. Age and sex effects on the pharmacokinetics of linezolid. Eur J Clin Pharmacol 2002;57:793-7.

11. Brier ME, Stalker DJ, Aronoff GR, et al. Pharmacokinetics of linezolid in subjects with renal dysfunction. Antimicrob Agents Chemother 2003;47:2775-80.

12. Stalker DJ, Jungbluth GL. Clinical pharmacokinetics of linezolid, a novel oxazolidinone antibacterial. Clin Pharmacokinet 2003;42:1129-40.

13. Green SL, Maddox JC, Huttenbach ED. Linezolid and reversible myelosuppression. JAMA 2001;285:1291.

14. Bernstein WB, Trotta RF, Rector JT, Tjaden JA, Barile AJ. Mechanisms for linezolid-induced anemia and thrombocytopenia. Ann Pharmacother 2003;37:517-20.

15. Yunis AA. Chloramphenicol toxicity: 25 years of research. Am J Med 1989;87:44N-48N. 


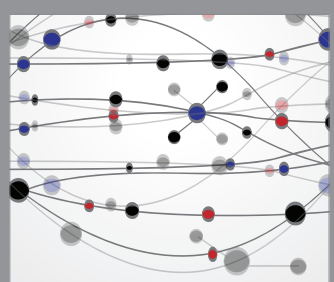

The Scientific World Journal
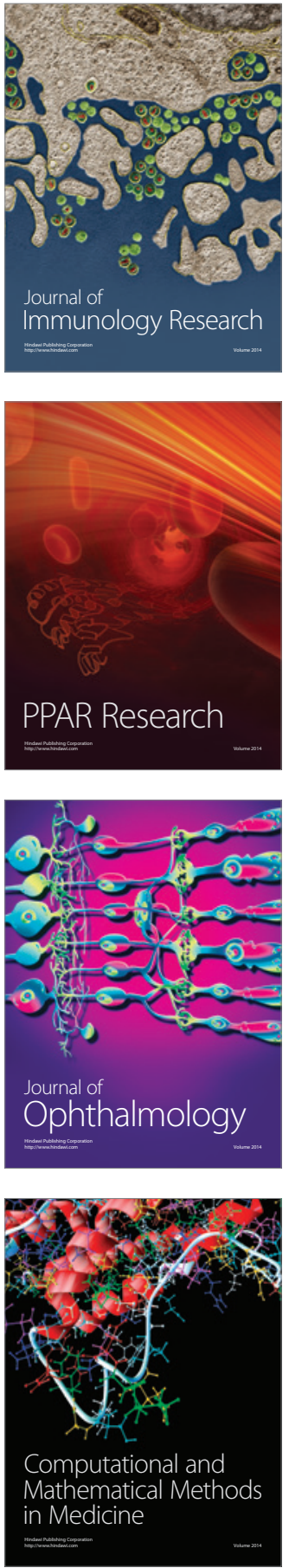

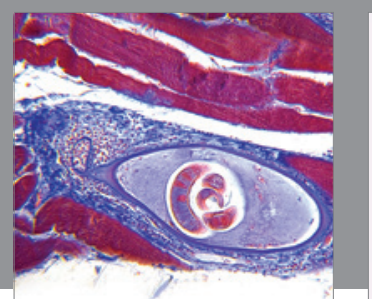

Gastroenterology Research and Practice

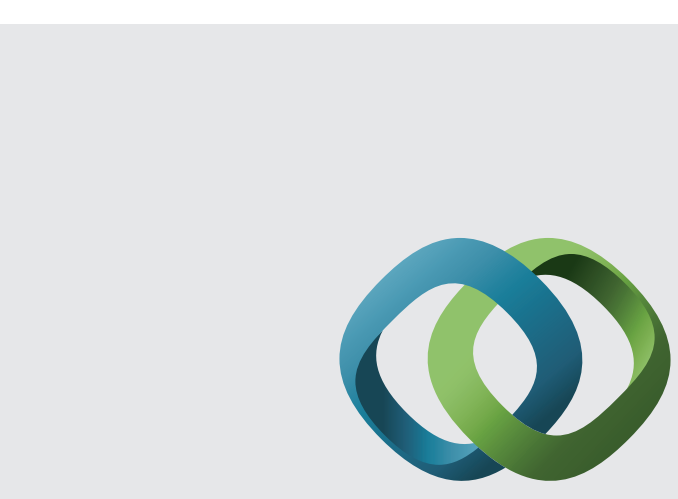

\section{Hindawi}

Submit your manuscripts at

http://www.hindawi.com
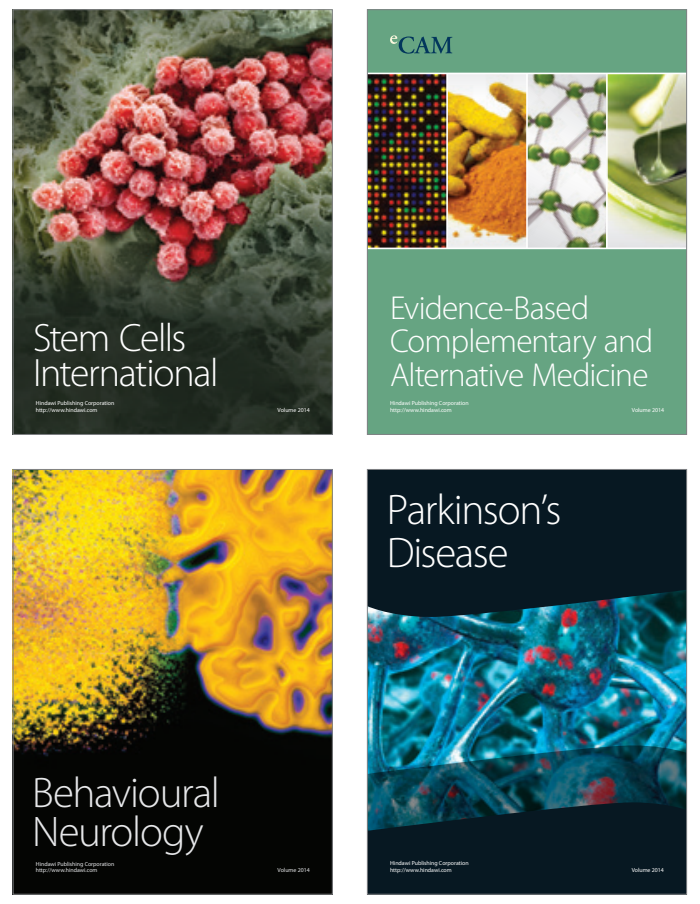
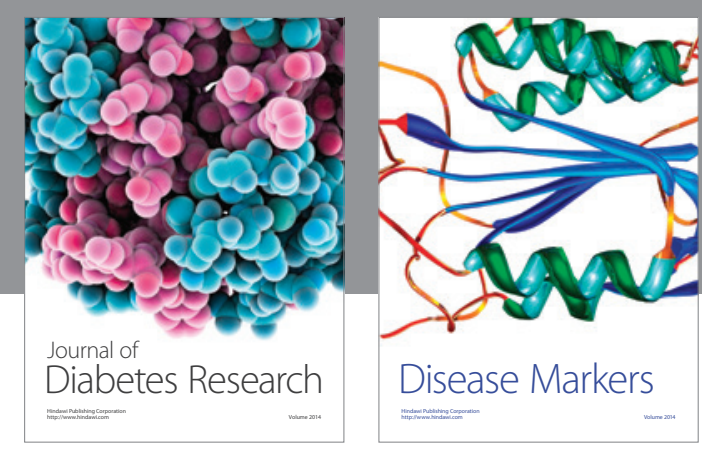

Disease Markers
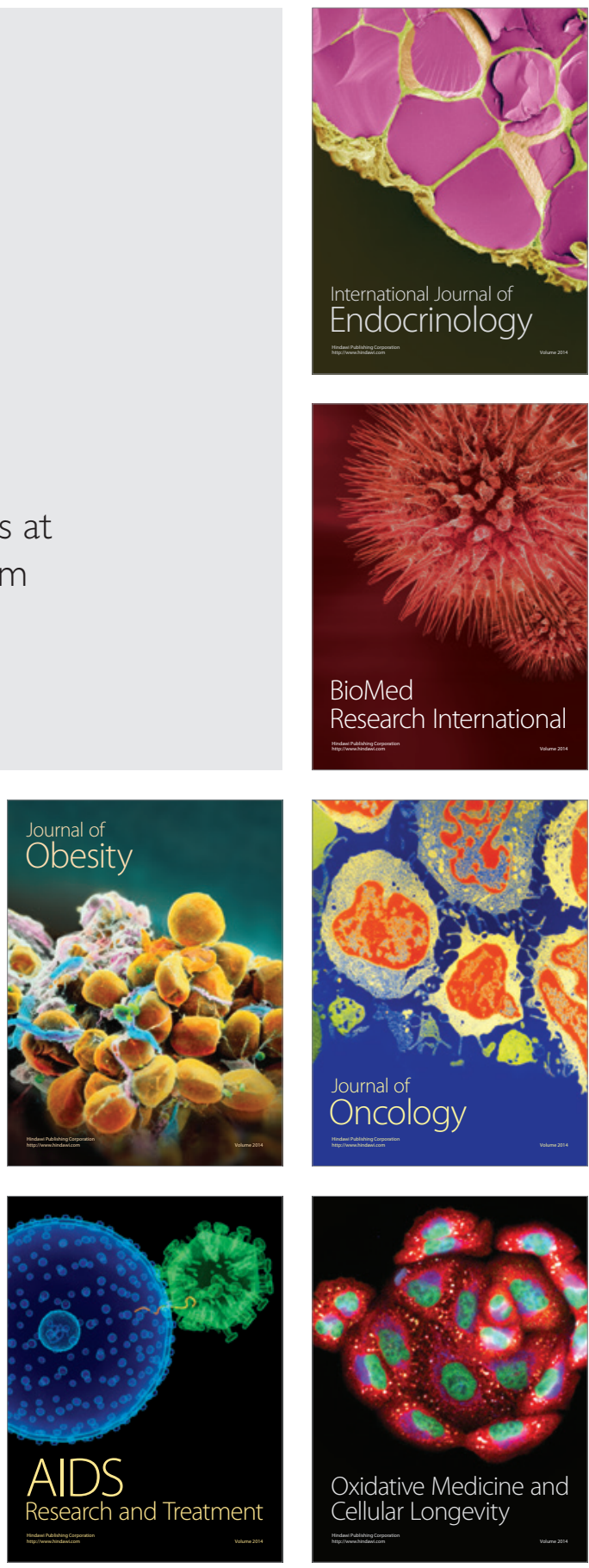